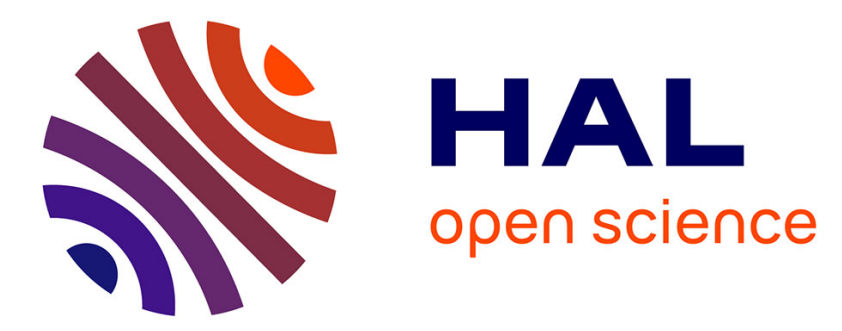

\title{
One-year follow-up of blood viscosity factors and hematocrit/viscosity ratio in elite soccer players
}

Jean-Frédéric Brun, Emmanuelle Varlet-Marie, Christine Fedou, E. Raynaud

\section{To cite this version:}

Jean-Frédéric Brun, Emmanuelle Varlet-Marie, Christine Fedou, E. Raynaud. One-year follow-up of blood viscosity factors and hematocrit/viscosity ratio in elite soccer players. Clinical Hemorheology and Microcirculation, 2017, 64 (4), pp.799 - 808. 10.3233/CH-168014 . hal-01803686

\section{HAL Id: hal-01803686 \\ https://hal.umontpellier.fr/hal-01803686}

Submitted on 30 Nov 2019

HAL is a multi-disciplinary open access archive for the deposit and dissemination of scientific research documents, whether they are published or not. The documents may come from teaching and research institutions in France or abroad, or from public or private research centers.
L'archive ouverte pluridisciplinaire HAL, est destinée au dépôt et à la diffusion de documents scientifiques de niveau recherche, publiés ou non, émanant des établissements d'enseignement et de recherche français ou étrangers, des laboratoires publics ou privés. 


\title{
One-year follow-up of blood viscosity factors and hematocrit/viscosity ratio in elite soccer players
}

\author{
Jean-Frédéric Brun ${ }^{\mathrm{a}, *}$, Emmanuelle Varlet-Marie ${ }^{\mathrm{b}, \mathrm{c}}$, Christine Fédou ${ }^{\mathrm{a}}$ \\ and Eric Raynaud de Mauverger ${ }^{\mathrm{a}}$ \\ ${ }^{\mathrm{a}}$ UMR CNRS 9214-Inserm U1046, «Physiopathologie \& Médecine Expérimentale du Cour et des \\ Muscles - PHYMEDEXP», Unité d'Explorations Métaboliques (CERAMM), Université de \\ Montpellier, Département de Physiologie Clinique, Hôpital Lapeyronie CHU Montpellier, France \\ ${ }^{\mathrm{b}}$ Institut des Biomolécules Max Mousseron (IBMM) UMR CNRS 5247, Université de Montpellier, \\ Ecole Nationale Supérieure de Chimie de Montpellier, France \\ ${ }^{ }$Laboratoire de Biophysique \& Bio-Analyses, Faculté de Pharmacie, Université de Montpellier, \\ France
}

Abstract. We investigated to what extent a prediction of the 'ideal' hematocrit based on individual hemorheological profile with an equation of viscosity is relevant in trained athletes, and how the agreement between theoretical and actual values is modified by changes in training volume and performance. Elite soccer players (national level: 18-32 yr, weight 61-83 kg, body mass index $20.9-25.8 \mathrm{~kg} / \mathrm{m}^{2}$ ) were seen twice at one year interval. Hemorheologic parameters were measured with the MT90 viscometer and the Myrenne aggregometer the theoretical bell-shaped curve of hematocrit/viscosity ratio as a function of hematocrit was reconstructed with Quemada's equation using actual plasma viscosity and red cell rigidity to predict hematocrit/viscosity at various hematocrit levels. RBC aggregation is correlated at baseline with fat mass $(\mathrm{M} 1=0.552$ $p<0.02)$ and changes in aggregation are related to changes in fat mass $(\mathrm{M}=0.652, p<0.05 ; \mathrm{M} 1=0.647, p<0.05)$. Predicted and actual hematocrit are correlated $(r=0.644, p<0.05)$ but exhibit discrepancies (mean difference $-1 \%$ range [3.24 to 1.24]) and those discrepancies are inversely correlated to the level of predicted hematocrit $(r=-0.912, p<0.01)$, to systolic blood pressure $(r=-0.626, p<0.05)$, and to the overtraining score $(r=-0.693, p<0.05)$. After one year changes in hematocrit are a close reflect of the change in training volume $(r=-0.877, p<0.01)$ but are not correlated to fitness changes. Therefore in these athletes i) systemic hematocrit is close to its predicted "ideal value", suggesting the accuracy of the prediction; ii) red cell aggregation is correlated to fat mass even in nonobese subjects; iii) hematocrit is lower than predicted by the model when markers of sympathetic tone (systolic blood pressure, overtraining score) are increased; iv) weekly training volume appears the main determinant of the reduction of hematocrit.

Keywords: Exercise, soccer, hematocrit/viscosity ratio, hemorheology, erythrocyte aggregation

\section{List of symbols}

RBC red blood cell

SEM standard error on the mean

${ }^{*}$ Corresponding author: Jean-Frédéric Brun, UMR CNRS 9214-Inserm U1046, " Physiopathologie \& Médecine Expérimentale du Cœur et des Muscles - PHYMEDEXP », Unité d'Explorations Métaboliques (CERAMM), Université de Montpellier, Département de Physiologie Clinique, Hôpital Lapeyronie CHU Montpellier, France. Tel.: +33 467338284; Fax +33 467338986; E-mail: j-brun@ chu-montpellier.fr. 


\section{Introduction}

Soccer is the sport were was initially described the "paradox of hematocrit", i.e. the fact that hematocrit is negatively correlated with markers of aerobic capacity and decreases after training, while doping by erythropoietin or autotransfusion is based on the opposite paradigm, i.e. the higher hematocrit, the higher performance [3-5].

The classical concept of hematocrit/viscosity $(h / \eta)$ ratio is likely in this context to be helpful for understanding this paradox. This parameter is theoretically proportional to the ability of blood to deliver oxygen, if one assumes that hematocrit reflects oxygen carrying by red cells while viscosity impairs blood flow. The ability of vessels to dilate in response to moderate increases in viscosity makes, obviously, this question more complex, but there is a large body of literature supporting the concept that $h / \eta$ is a statistical determinant of $\mathrm{O}_{2}$ supply to tissues [21].

Our purpose was thus to propose a theoretical prediction of 'optimal' hematocrit and $h / \eta$ in athletes on the basis of a widely admitted equation of blood viscosity, and to compare it to the actual value, and to see how the agreement between theoretical and actual values is modified by changes in training volume and performance.

\section{Subjects and methods}

\subsection{Study subjects}

A sample of elite soccer players (national level: $18-32 \mathrm{yr}$, weight $61-83 \mathrm{~kg}$, body mass index $20.9-25.8 \mathrm{~kg} / \mathrm{m}^{2}$ ). Characteristics of patients are shown on Table 1 . Their mean systolic blood pressure $11.4 \pm 0.19 \mathrm{cmHg}$ and their mean diastolic blood pressure was $7.25 \pm 0.14$. Their eating habits collected with an autoquestionnaire and further calculated with a program as previously reported [12] were $2380 \pm 149$ calories, with $40 \pm 4 \%$ carbohydrates, $51 \pm 4 \%$ lipids, $10.4 \pm 0.5$ proteins, i.e. a daily protein intake evaluated at $0.77 \pm 0.05 \mathrm{~g} / \mathrm{kg} /$ day. Subjects were seen at the same time of the season one year later. Maximal aerobic capacity $\left(\mathrm{VO}_{2} \max \mathrm{ACSM}\right)$ was assessed from the submaximal steps according to the American College of Sports Medicine [8]. In addition to a complete clinical examination, the French questionnaire of early symptoms of overtraining developed by the French Society for Sports Medicine (SFMS) downloadable on the website of this society at $<$ http://www.sfmes.org/images/sfmes/pdf/consensus_3.pdf> was employed.

\subsection{Bioelectrical impedance measurements}

Prior to the exercise-test, subjects' body composition was assessed with bioimpedance analysis with a six terminal impedance plethismograph Biacorpus RX4000, (Healthnesslink, 8 avenue

Table 1

Clinical characteristics of the study subjects (mean + SEM)

\begin{tabular}{lr}
\hline Age (years) & $24.8 \pm 1.00$ \\
Fat-free mass $(\mathrm{kg})$ & $66.54 \pm 1.33$ \\
Fat mass $(\mathrm{kg})$ & $7.88 \pm 0.36$ \\
Body mass index $\left(\mathrm{kg} / \mathrm{m}^{2}\right)$ & $23.57 \pm 0.30$ \\
Number of hours weekly training & $10.59 \pm 0.52$ \\
Overtraining score & $4.00 \pm 0.86$ \\
$\mathrm{VO}_{2} \mathrm{max}(\mathrm{ml} / \mathrm{min} / \mathrm{kg})$ & $52.70 \pm 1.85$ \\
$\mathrm{VO}_{2} \mathrm{max}(\%$ theoretical prediction) & $126.7 \% \pm 3.8 \%$ \\
\hline
\end{tabular}


Jean-Jaurès 92130 Issy-les-Moulineaux, France) with data analysis with the software BodyComp 8.4. This device measures total resistance of the body to an alternative electric current of $50 \mathrm{kHz}$.

\subsection{Hemorheological ex vivo measurements}

Blood samples for hemorheological measurements $(7 \mathrm{ml})$ were drawn with potassium EDTA as the anticoagulant in a vacuum tube (Vacutainer). Viscometric measurements were done at very high shear rate $\left(1000 \mathrm{~s}^{-1}\right)$ with a falling ball viscometer (MT 90 Medicatest, F-86280 Saint Benoit). The coefficient of variation of this method ranges between 0.6 and $0.8 \%$. We measured with this device apparent viscosity of whole blood at native hematocrit, plasma viscosity, and blood viscosity at corrected hematocrit (45\%) according to the equation of Quemada [15].

$$
\eta=\eta_{p}(1-1 / 2 \mathrm{k} \phi)^{-2}
$$

- where $\phi$ is hematocrit, $\eta_{\mathrm{p}}$ is plasma viscosity, and $\mathrm{k}(\gamma)$ is a shear-dependent parameter quantifying the contribution of erythrocyte rheological properties to whole blood viscosity.

- At the high shear rate used here $\mathrm{k}(\gamma)$ is representative of red cell rigidity (i.e., the lower $\mathrm{k}(\gamma)$, the higher is erythrocyte deformability).

With this equation it is possible to standardize $\eta$ for hematocrit $45 \%$ after calculating $\mathrm{k}$ :

$$
\mathrm{k}=2 \cdot\left(1-\eta \mathrm{r}^{-0.5}\right) \cdot \phi^{-1}
$$

This value of $\mathrm{k}$ is reintroduced in Equation (1) with $\phi$ set at 0.45 . Dintenfass's 'Tk' index [6] was also calculated as an index of red cell rigidity.

RBC aggregation was assessed with the Myrenne aggregometer [16] which gives two indices of RBC aggregation: "M" (aggregation during stasis after shearing at $600 \mathrm{~s}^{-1}$ ) and "M1" (facilitated aggregation at low shear rate after shearing at $600 \mathrm{~s}^{-1}$ ). Hematocrit was measured with microcentrifuge.

\subsection{Prediction of the theoretical optimal hematocrit and hematocrit viscosity ratio}

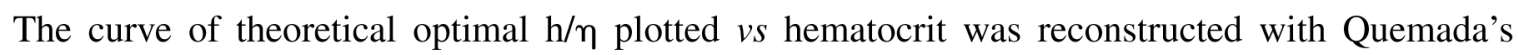
equation presented above. The equation of $h / \eta$ as a function of $h$ was thus:

$$
\mathrm{h} / \eta=\mathrm{h} /\left[\eta_{\mathrm{p}}(1-1 / 2 \mathrm{k} \phi)^{-2}\right]
$$

The hematocrit corresponding to the top of this curve was considered as the "theoretical optimal hematocrit". The highest value of $h / \eta$ (the top of the curve) was considered as the optimal $h / \eta$.

\subsection{Statistics}

Values are presented as mean \pm standard error of the mean (SEM). Normality of samples was checked with the Kolmogorov-Smirnov test. After verification of normality, we used ANOVA followed by posthoc Student's $t$ test for paired samples. Correlations were assessed with Pearson's procedure (least square fitting). A value of $p<0.05$ was considered as significant. 


\section{Results}

\subsection{Evolution of anthropometric and ergometric parameters}

Since there was not a training study but a follow-up in stable conditions, there was no overall change in fitness or blood viscosity. After one year non significant tendency to a decrease in the mean training volume (hrs/wk) as assessed by questionnaire. At the beginning they exercised $11 \pm 1 \mathrm{hr} / \mathrm{wk}$ and one year later they exercised $9 \pm 1 \mathrm{hr} / \mathrm{wk}$. This weekly volume of training decreased in 4 subjects and increased in 5 .

\subsection{Hemorheologic parameters}

Figure 1 shows the curve of theoretical optimal $h / \eta$ plotted vs hematocrit reconstructed with Quemada's equation. This picture shows that on the average the actual values of hematocrit and $\mathrm{h} / \eta$ exhibit a nonsignificant tendency to be lower than predicted with the model.

As shown on Table 2, after one year non significant tendency to a decrease in hematocrit, that was $42.78 \pm 0.52 \%$ at the beginning of the study and $41.67 \pm 1.08 \%$ one year later.

\subsection{Correlations}

As shown on Fig. 2, after one year, changes in hematocrit are a close reflect of the change in training volume $(r=-0.877, p<0.01)$. By contrast (data not shown), the correlation between hematocrit and
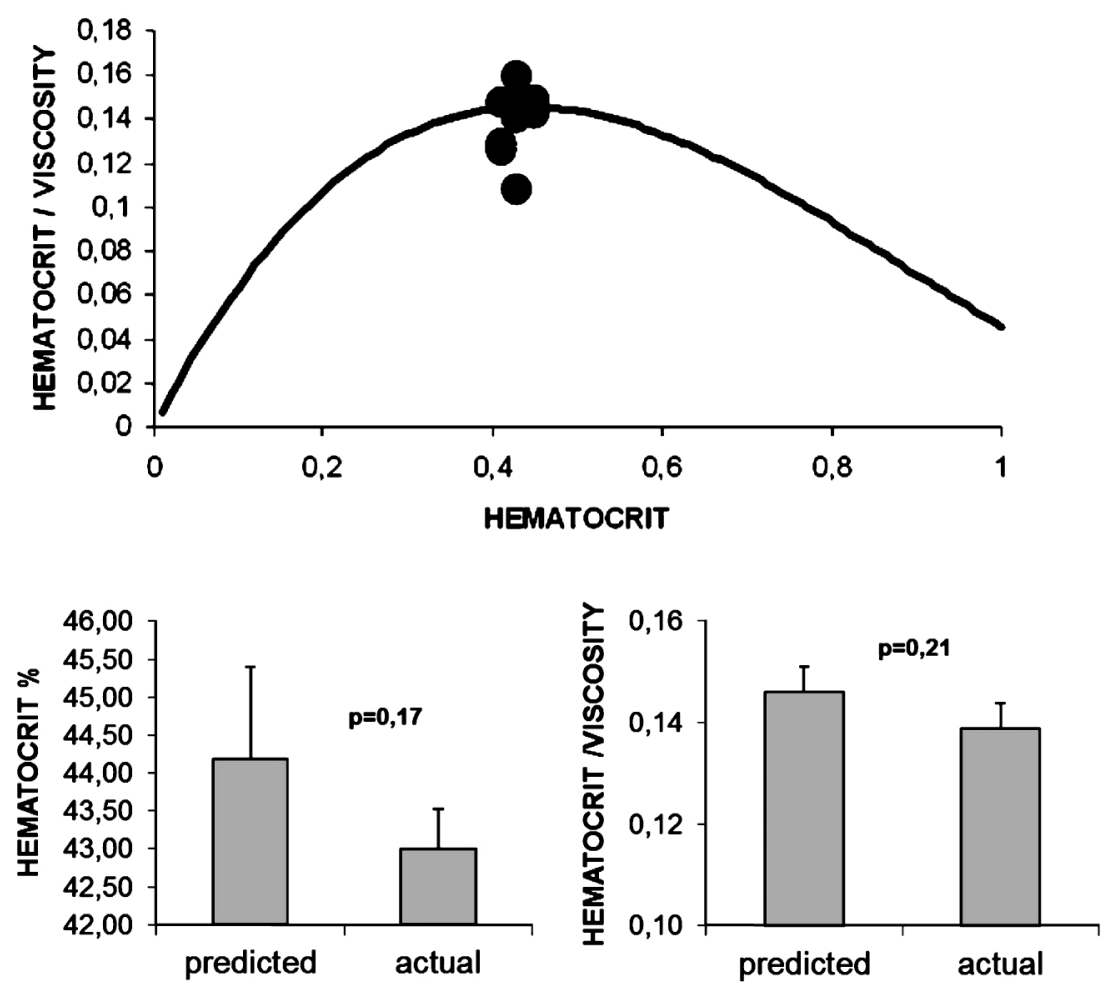

Fig. 1. Upper panel. Reconstruction of the theoretical bell-shaped curve of $h / \eta$ from native viscosity factors with Quemada's formula. Full black circles = actual values. Lower panel: Comparison of predicted optimal values of hematocrit (left) and hematocrit/viscosity ratio with the actual ones, showing a non significant trend toward a value lower than predicted of these two parameters. 
Table 2

Hemorheological parameters at baseline and one year later (mean + SEM).

No significant difference after one year

\begin{tabular}{lrr}
\hline & \multicolumn{1}{c}{ Baseline } & One year later \\
\hline Hematocrit (\%) & $42.78 \pm 0.52$ & $41.67 \pm 1.08$ \\
Plasma viscosity (mPa.s) & $1.57 \pm 0.03$ & $1.47 \pm 0.07$ \\
Whole blood viscosity (mPa.s) & $3.13 \pm 0.12$ & $3.14 \pm 0.02$ \\
RBC rigidity "k" (Quemada) & $1.35 \pm 0.09$ & $1.54 \pm 0.10$ \\
RBC aggregation 'M' & $4.98 \pm 0.51$ & $5.74 \pm 0.45$ \\
RBC aggregation 'M1' & $9.01 \pm 0.63$ & $9.63 \pm 0.60$ \\
\hline
\end{tabular}

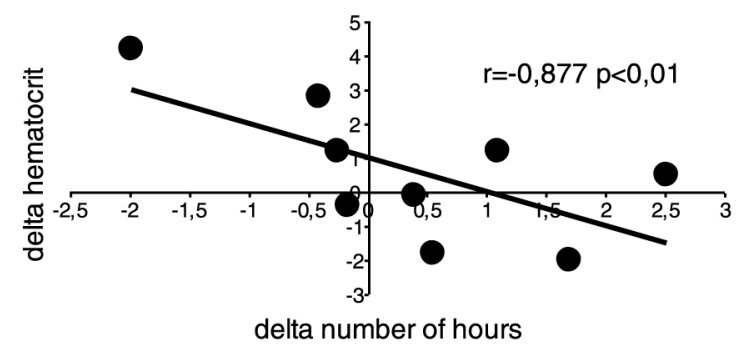

Fig. 2. Negative correlation between the change in weekly exercise volume over one year and the change in hematocrit over the same period, showing that increasing the number of hours of exercise per week is associated with a decrease in hematocrit.

aerobic capacity is not found in this sample ( $r=0.075$ before the year of follow-up and $r=0.093$ after the year of follow-up).

As shown on Fig. 3, RBC aggregation is correlated at baseline with fat mass ('M1' $=0.552, p<0.02$ ) and changes in aggregation are related to changes in fat mass (' $\mathrm{M}$ ' $=0.652, p<0.05$; 'M1' $=0.647$, $p<0.05)$.

\subsection{Agreement between theoretical and actual values of hematocrit and $h / \eta$}

As shown on Fig. 4, predicted and actual hematocrit are correlated but exhibit discrepancies (mean difference $-1 \%$ range [ 3.24 to 1.24 ]). Figure 5 shows that these discrepancies are correlated with two parameters: the value of predicted hematocrit $(r=-0.912, p<0.01)$, and the clinical score of overtraining $(r=-0.693, p<0.05)$. In addition discrepancies are also correlated to diastolic blood pressure $(r=0.626, p<0.05)$ but neither systolic blood pressure $(r=-0.572$, NS), pulse pressure $(r=-0.409$, NS), nor mean blood pressure $(r=0.314, \mathrm{NS})$.

\section{Discussion}

This study shows in a sample of elite athletes that Quemada's equation predicts an optimal value hematocrit which is very close to the actual one, suggesting that this calculation predicts rather accurately the 'ideal' hematocrit, and that this actual hematocrit is set very close to this 'ideal' value. However hematocrit is lower on the average than this model-predicted "ideal value" when markers of sympathetic tone (systolic blood pressure, overtraining score) are moderately increased. Weekly 
$r=0.448 \mathrm{~ns}$
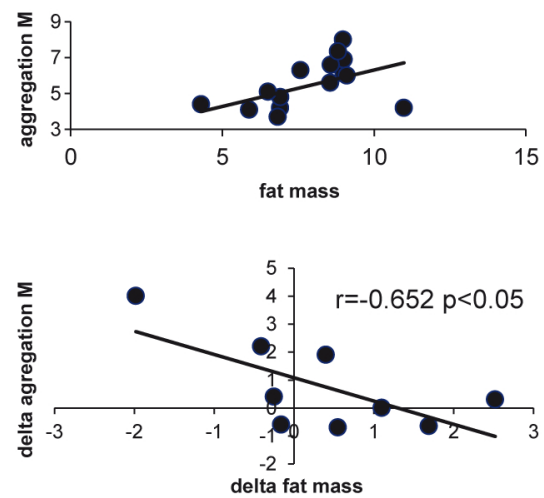

$r=0.552 p<0.02$
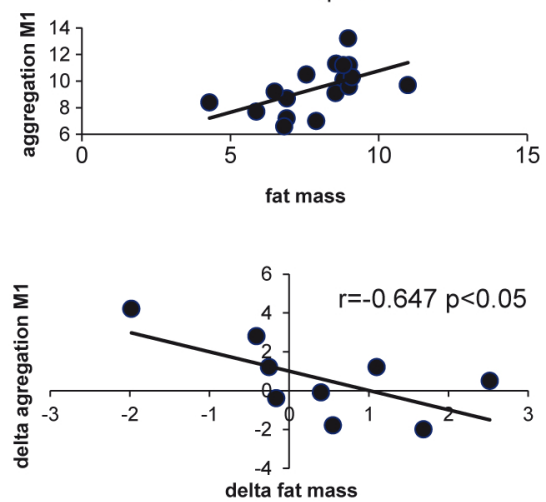

Fig. 3. Correlations between RBC aggregation and fat mass. On the upper panel are shown the crude correlations of the two aggregation indices with fat mass expressed in $\mathrm{kg}$. On the lower panel are shown the correlations between the changes in fat mass over the period of 1 year and the changes in aggregation indices.

training volume rather than fitness appears the main determinant of training-induced reduction of hematocrit. Red cell aggregation is correlated to fat mass within a physiological range.

This study has the advantage of representing a follow-up in real life conditions, with some subjects undergoing an increase in their aerobic performance and some others undergoing a decrease.

Since the prediction is based on the $h / \eta$ paradigm, the agreement between predicted and actual values supports to some extent this classical concept. Our data are consistent with the hypothesis that there is a homeostatic mechanism aiming at maintaining $h / \eta$ close from its optimal value defined by the top of the bell-shaped curve of $h / \eta$ plotted as a function of hematocrit. Two mechanisms of 'viscoregulation' have been until now evidenced: the modulation of hematocrit by a loop involving the hormone erythropoietin and triggered by plasma viscosity [17] and the decrease in red cell rigidity as a response to excessive erythrocytosis [20]. Both mechanisms prevent excess blood viscosity. In other terms, not surprisingly, hematocrit which is the most important determinant of blood viscosity is the pivotal parameter in viscoregulation, being both a stimulus and a regulated parameter.

Our modelling approach requires some comments. The equation of Quemada [15] is a prediction of blood viscosity from hematocrit, plasma viscosity and a red cell rheology factor ' $\mathrm{k}$ ' that represents red cell rigidity when the measurements are performed, as done in this study, at high shear rate.

It is well known that hematocrit is not the same in various territories of circulation, and can undergo huge variations according to physiological conditions. For example Vicaut reported in studies on rat myocardium a sub-epicardial hematocrit of $33.1 \pm 0.6 \%$ while systemic hematocrit was $39.9 \pm 2.2 \%$ [19]. Okazawa [14] found in human brain $38.3 \pm 3.5 \%$ while systemic hematocrit was $43.5 \pm 4.1 \%$. Lipowsky [11] in 10-15 $\mu \mathrm{m}$ arterioles and venules of cat mesentery reported a microvascular hematocrit of $8.2 \pm 4.3 \%$ while systemic hematocrit was $35.5 \pm 5.6 \%$. Klitzman [10] in $15 \mu \mathrm{m}$ arterioles of hamster cremaster muscle found a local hematocrit of $13.9 \pm 1.2 \%$ while systemic hematocrit was $49.4 \pm 1.1 \%$. Despite some controversies and the differences among methodologies it is clear that in local circulations hematocrit is lower, and sometimes much lower, than the systemic one, and can undergo very important changes in physiological conditions, such as exercise [9].

Our data deal with systemic hematocrit which is thus higher than these local hematocrits and show that the predicted 'optimal' value seems to represent an upper limit of systemic hematocrit in physiological conditions.

We should also point out that our measurements are relevant to venous blood in which the shear rate is lower than that employed in our viscometric measurements. Actually it seems that the concept of $\mathrm{h} / \eta$ 

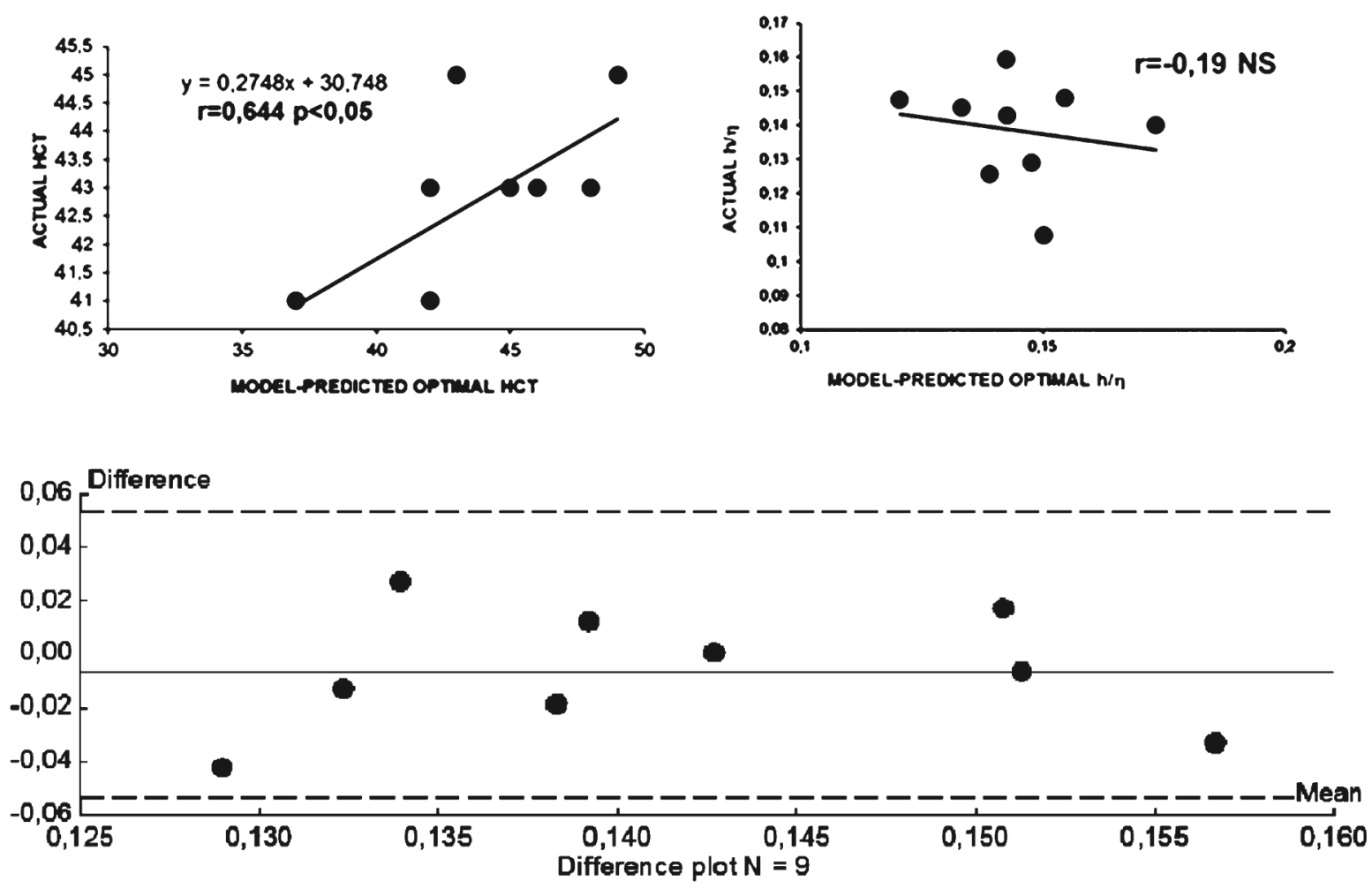

Mean difference : $-0,00637[-0,0241$ to 0,0114$]$

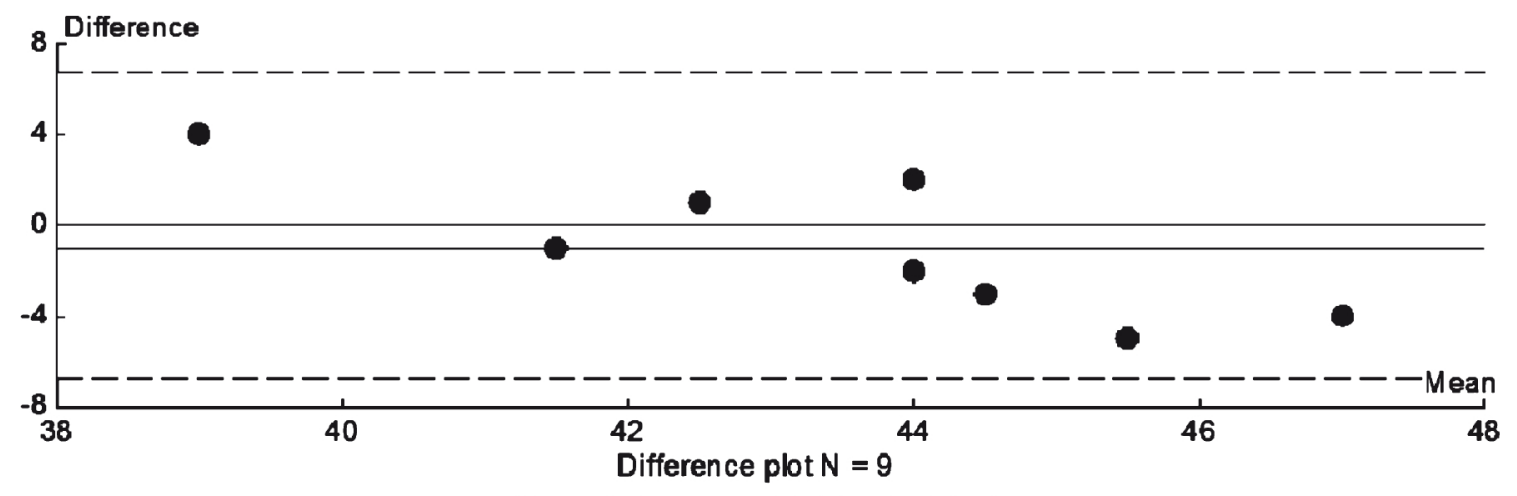

Mean difference : $-1[-3,24$ to 1,24$]$

Fig. 4. Agreement between theoretical and actual values of hematocrit and hematocrit/viscosity ratio. Upper panel: Correlations, showing that actual hematocrit is correlated to its theoretical predicted optimal value while hematocrit/viscosity ratio is not. Lower panel: Bland-Altman plots analyzing the discrepancy for both parameters between the theoretical and the actual value. For hematocrit the mean difference $-1 \%$ means that on the average actual hematocrit tends to be lower than the theoretical 'optimal' value.

is mostly relevant for measurements at high shear rate. With lower shear rates the curve of $h / \eta$ plotted as a function of hematocrit loses its bell-shaped aspect and it is no longer possible to detect its top [13], probably due to the more complex effect of red cell aggregation. Therefore what we report here is probably not relevant to venous physiology but rather to the arterial bed in which hematocrit is close to the venous one. Most of the time arterial hematocrit is said to be lower than the venous one, as found for example by Yang et al. [22] who reports an average difference of $3.1 \%$. However this difference 
volume (while hematocrit in this study is not correlated to aerobic capacity) is in line with the notion that repeated bouts of exercise result in a 'hemodilution' prolonged over a couple of days. Therefore the negative correlations repeatedly reported between fitness and hematocrit may be largely explained by the covariable 'exercise volume' which is closely related to both of them. This specific issue will require additional studies.

\section{Conclusions}

In conclusion, this study shows that in a team of professional soccer players venous hematocrit is set close to its theoretical 'optimal' value as predicted with a classical equation of viscosity. The fair agreement between the theoretical prediction and the actual value supports the theory of 'optimal hematocrit' and its determination with the bell shaped curve of $h / \eta$ as a function of hematocrit. However the discrepancies between the theoretical and the actual hematocrit remain to be further analyzed.

Besides, we confirm that RBC aggregation is related to fat mass also in lean subjects and not only in obese, indicating that fat mass is a major regulator of RBC aggregation.

Finally, the strong relationship between changes in training volume and changes in hematocrit is also appealing, indicating that low hematocrit in athletes may be rather a marker of training volume than fitness.

\section{Acknowledgments}

The authors affirm that they have no disclosure of interest concerning the issue investigated in this paper. This study was presented at the 15th International Congress of Biorheology and 8th International Conference on Clinical Hemorheology. May 24-28, 2015, Seoul, Korea.

\section{References}

[1] S. Awasthi, R. Rani and D. Malviya, Peripheral venous blood gas analysis: An alternative to arterial blood gas analysis for initial assessment and resuscitation in emergency and intensive care unit patients, Anesthesia: Essays and Researches (serial online) 7 (2013), 355-358.

[2] A.D. Blann, R.A. Adams, F. Katai, R. Ashleigh and D.A. Taberner, Haematology and coagulation indices in paired samples of arterial and venous blood from patients with arterial disease, Haemostasis 26 (1996), 72-78.

[3] J.-F. Brun, C. Bouchahda, D. Chaze, A. Benhaddad, J.-P. Micallef and J. Mercier, The paradox of hematocrit in exercise physiology: Which is the "normal" range from an hemorheologist's viewpoint? Clinical Hemorheology and Microcirculation 22 (2000), 287-303.

[4] J.-F. Brun, P. Connes and E. Varlet-Marie, Alterations of blood rheology during and after exercise are both consequences and modifiers of body's adaptation to muscular activity, Science \& Sports 22 (2007), 251-266.

[5] J.-F. Brun, E. Varlet-Marie, P. Connes and I. Aloulou, Hemorheological alterations related to training and overtraining, Biorheology 47(2) (2010), 95-115.

[6] L. Dintenfass, Blood viscosity, Hyperviscosity \& Hyperviscosaemia. Melbourne, MTP press, 1985, pp. 482.

[7] R.J. Frumento, A.L. Hirsh, M.K. Parides and E. Bennett-Guerrero, Differences in arterial and venous thromboelastography parameters: Potential roles of shear stress and oxygen content, Journal of Cardiothoracic and Vascular Anesthesia 16 (2002), 551-554.

[8] S. Glass and B. Gregory, ACSM's Metabolic Calculations Handbook, Lippincott Williams \& Wilkins, Baltimore, 2007 , pp. $25-74$.

[9] C.A. Kinding, T.E. Richardson and D.C. Poole, Skeletal muscle capillary hemodynamics from rest to contractions: Implications for oxygen transfer, Journal of Applied Physiology 92(6) (2002), 2513-2520.

[10] B. Klitzman and B.R. Duling, Microvascular hematocrit and red cell flow in resting and contracting striated muscle, American Journal of Physiology 237 (1979), H481. 
[11] H.H. Lipowsky and S. Kovalcheck, The distribution of blood rheological parameters in the microvasculature of cat mesentery, Circulation Research 43(5) (1978), 738-749.

[12] J. Manetta, S. Khaled, D. Bouix, K. Krechiem, J.-F. Brun and A. Orsetti, Evaluation d'un auto questionnaire alimentaire court par comparaison avec un entretien diététique chez des sujets sportifs et sédentaires, Science \& Sports 12 (1997), 210-213.

[13] N. Nemeth, T. Alexy, A. Furka, O.K. Baskurt, H.J. Meiselman, I. Furka and I. Miko, Inter-species differences in hematocrit to blood viscosity ratio, Biorheology 46(2) (2009), 155-165.

[14] H. Okazawa, Y. Fujibayashi, Y. Yonekura, N. Tamaki, S. Nishizawa, Y. Magata, K. Ishizu, T. Tsuchida, N. Sadato and J. Konishi, Measurement of regional cerebral plasma pool and hematocrit with copper-62-labeled HSA-DTS, Journal of Nuclear Medicine 37(7) (1996), 1080-1085.

[15] D. Quemada, Rheology of concentrated disperse systems. II. A model of non newtonian shear viscosity in steady flows, Rheologyca Acta 17 (1978), 632-642.

[16] H. Schmid-Schönbein, E. Volger and H.J. Klose, Microrheology and light transmission of blood III: The velocity of red cell aggregate formation, Pflugers Archiv European Journal of Physiology 254 (1975), 299-317.

[17] A. Singh, K.U. Eckardt, A. Zimmermann, K.H. Götz, M. Hamann, P.J. Ratcliffe, A. Kurtz and W.H. Reinhart, Increased plasma viscosity as a reason for inappropriate erythropoietin formation, Journal of Clinical Investigation 91(1) (1993), 251-256.

[18] K.H. Son, C.H. Lim, E.J. Song, K. Sun, H.S. Son and S.H. Lee, Inter-species hemorheologic differences in arterial and venous blood, Clinical Hemorheology and Microcirculation 44 (2010), 27-33.

[19] E. Vicaut and B.I. Levy, Transmural hematocrit gradient in left ventricular myocardia of rats, American Journal of Physiology 259(2 Pt 2) (1990), H403-408.

[20] J. Vogel, I. Kiessling, K. Heinicke, T. Stallmach, P. Ossent, O. Vogel, M. Aulmann, T. Frietsch, H. Schmid-Schönbein, W. Kuschinsky and M. Gassmann, Transgenic mice overexpressing erythropoietin adapt to excessive erythrocytosis by regulating blood viscosity, Blood 102(6) (2003), 2278-2284.

[21] X. Waltz, M.-D. Hardy-Dessources, N. Lemonne, D. Mougenel, M.-L. Lalanne-Mistrih, Y. Lamarre, V. Tarer, B. Tressières, M. Etienne-Julan, O. Hue and P. Connes, Is there a relationship between the hematocrit-to-viscosity ratio and microvascular oxygenation in brain and muscle? Clinical Hemorheology and Microcirculation 2 (2015), $37-43$.

[22] Z.W. Yang, S.H. Yang and L. Chen, J. Qu, J. Zhu and Z. Tang, Comparison of blood counts in venous, fingertip and arterial blood and their measurement variation, Clinical \& Laboratory Haematology $\mathbf{2 3}$ (2001), 155-159. 